\title{
Alterstice
}

Revue internationale de la recherche interculturelle

International Journal of Intercultural Research

Revista International de la Investigacion Intercultural

\section{Domestic violence, ethnic diversity, and political and economic change in an upland community of Vietnam}

\section{Lynn Kwiatkowski}

Volume 3, numéro 2, 2013

Violence conjugale et diversité culturelle

URI : https://id.erudit.org/iderudit/1077520ar

DOI : https://doi.org/10.7202/1077520ar

Aller au sommaire du numéro

Éditeur(s)

Alterstice

ISSN

1923-919X (numérique)

Découvrir la revue

Citer cet article

Kwiatkowski, L. (2013). Domestic violence, ethnic diversity, and political and economic change in an upland community of Vietnam. Alterstice, 3(2), 51-65. https://doi.org/10.7202/1077520ar

\section{Résumé de l'article}

Domestic violence occurs among a variety of ethnic groups in Vietnam, within diverse social, cultural, and environmental contexts. This article explores the role that culture is perceived to play in influencing manifestations of domestic violence among different ethnic groups living in the same community in Vietnam, in relation to the social structural influences on this form of gender violence. It examines the perceptions of wife abuse among members of three ethnic groups - the Kinh, Muong, and Dao-living in an upland community in a province in northern Vietnam. In this article, first, domestic violence is situated among the ethnic groups, who live within a changing social, political, and economic environment, through an exploration of the reasons members of the ethnic groups offered for husbands' abuse of their wives. Second, problems abused women continue to face, despite the implementation of a new domestic violence law, and new orientations among professionals and community leaders toward provision of services for abused women are assessed. 


\section{7}

alterstice

ARTICLE THÉMATIQUE

\section{Domestic violence, ethnic diversity, and political and economic change in an upland community of Vietnam}

Lynn Kwiatkowski

\section{Résumé}

Domestic violence occurs among a variety of ethnic groups in Vietnam, within diverse social, cultural, and environmental contexts. This article explores the role that culture is perceived to play in influencing manifestations of domestic violence among different ethnic groups living in the same community in Vietnam, in relation to the social structural influences on this form of gender violence. It examines the perceptions of wife abuse among members of three ethnic groups - the Kinh, Muong, and Dao-living in an upland community in a province in northern Vietnam. In this article, first, domestic violence is situated among the ethnic groups, who live within a changing social, political, and economic environment, through an exploration of the reasons members of the ethnic groups offered for husbands' abuse of their wives. Second, problems abused women continue to face, despite the implementation of a new domestic violence law, and new orientations among professionals and community leaders toward provision of services for abused women are assessed.

\section{Rattachement de l'auteure \\ ${ }^{1}$ Department of Anthropology, Colorado State University, États-Unis}

\section{Correspondance}

lynn.kwiatkowski@colostate.edu

\section{Mots clés}

domestic violence; ethnicity; political economy of gender violence; Vietnam

\section{Pour citer cet article :}

Kwiatkowski, L. (2013). Domestic violence, ethnic diversity, and political and economic change in an upland community of Vietnam. Alterstice, 3(2), 51-65. 


\section{Introduction}

Domestic violence occurs among a variety of ethnic groups in Vietnam, within diverse social, cultural, and environmental contexts. Culture plays an important role in shaping and giving meaning to domestic violence, in Vietnam and elsewhere (Alcalde, 2010; Burbank, 1994; Hautzinger, 2007; Lazarus-Black, 2007; Merry, 2009; Parson, 2013). This article explores the role that culture is perceived to play in influencing manifestations of domestic violence among different ethnic groups living in the same community in Vietnam, in relation to the social structural influences on this form of gender violence. It examines the perceptions of wife abuse among members of three ethnic groups - the Kinh, Muong, and Dao-living in an upland community in a province in northern Vietnam. These perceptions include those of women who have been abused by their husband, as well as the perceptions of other community members.

In spite of the significant role of culture, few local leaders and healers interviewed in this community perceived or reported significant differences in the experiences of domestic violence among members of each ethnic group, although a small number did. In contrast, political and economic forces appear to have more significantly influenced the experiences of domestic violence for women who are members of these ethnic groups than cultural differences among the ethnic groups. These political and economic forces include the Vietnamese government's shift from a planned to a socialist-oriented market economy, or market socialism, that came about through economic and social reforms referred to as doi moi; the implementation of a new domestic violence law in the context of economic and social change in Vietnamese society; and changing state orientations toward minority ethnic groups. This study argues that the intersection of state power, structural processes, and shared cultural conceptions and dominant discourses of gender, marriage, family and violence has played an integral role in shaping abused women and abusive men's experiences of domestic violence among members of the three ethnic groups living in the research community.

\section{Objectives}

While much research has addressed domestic violence among members of the Kinh majority ethnic group in Vietnam, little research has been conducted with members of ethnic minority groups addressing this or other forms of gender violence (Gammeltoft, 1999; Hoang, 2005; Kwiatkowski, 2011a, 2011b, 2011c, 2011d, 2012; Le, T. P. M., 1998, 2002; Le, T. Q., 1992, 1996, 2000, 2004; Luke, Schuler, Bui, Pham, \& Tran, 2007; Nguyen, Ostergren, \& Krantz, 2008; Nguyen, Vu, \& The Centre for Reproductive and Family Health Project Officers, 2001; Phan, 2008; Romedenne \& Vu, 2006; Rydstrom, 2003; Vu, Vu, Nguyen, \& Clement, 1999). In this article, first, domestic violence is situated among the Kinh, Muong, and Dao living in the upland community within a changing social, political, and economic environment through an exploration of the reasons members of these ethnic groups offered for husbands' abuse of their wives. Tracked are the linkages between the political and economic changes that have occurred in Vietnam in recent years and men's ability to commit violence against their wives among members of these three ethnic groups. By taking this approach, men's violence against their wives and other community members' responses to this violence are more clearly understood to be situated within a context of changing social structural conditions (Merry, 2009; Padilla, 2011).

Second, problems abused women continue to face, despite the implementation of the new domestic violence law, and new orientations among professionals and community leaders toward provision of services for abused women are assessed. How domestic violence is responded to at the local level in the upland community is addressed, with contemporary responses having been influenced by Western conceptions of and approaches to domestic violence introduced by international donors and nongovernmental organizations (NGOs) and taken up by local Vietnamese mass organizations, officials, NGOs, and policy makers. The new orientations stem in part from ongoing negotiations among members of local NGOs, international organizations, and state agencies and organizations, and link members of ethnic minority groups in Vietnam to global social movements against violence to women.

Alterstice - Revue Internationale de la Recherche Interculturelle, vol. 3, $n^{\circ} 2$ 


\section{Research Methods}

This article is based on my qualitative ethnographic fieldwork focusing on domestic violence, and wife abuse in particular, conducted over a two-and-a-half-month period in 2010 among members of the Muong and Dao ethnic minority groups and the Kinh ethnic majority group living in two communes of an upland province in northern Vietnam. This research consisted of participant observation in the community, informal interviews with community members, and formal interviews with research participants from each of the three ethnic groups. Formal, in-depth, semi-structured, open-ended interviews with an adult representative of 39 families of the three ethnic groups were conducted, with almost equal numbers of Muong, Kinh, and Dao men and women (including six Muong men, six Muong women, seven Dao men, eight Dao women, six Kinh men, and six Kinh women). These study participants worked as farmers, teachers, domestic workers, wage laborers, drivers of vehicles, home-based producers of products such as wine and tofu, market salespersons, mechanics, small business owners, carpenters, construction workers, and part-time musicians. Some of these participants engaged in a combination of these types of work, and a few were retired. Thirteen of these individuals identified as members of families with low income levels, 14 with middle income levels, and 12 with higher income levels. In addition, formal, in-depth, semi-structured, open-ended interviews were conducted with 15 women who had experienced, or were then currently experiencing, domestic violence, with five women from each of the three ethnic groups. These women worked mainly as farmers, and also as factory workers, market salespersons, part-time health workers, wage workers, and teachers, and, like the representatives of families, with some engaging in a combination of these types of work. Eight of the women identified as members of families with low income levels, and seven with middle income levels. The study also included formal semi-structured, open-ended interviews with 24 state and non-state officials and state supported leaders, health care personnel, local healers, and other key informants who lived in these two communes. Most of these individuals participated in activities to prevent and intervene in domestic violence cases and to assist women who had been abused by their husbands. These community leaders and healers included 11 men and 13 women from the three ethnic groups who were members of official local reconciliation committees, tasked to reconcile conflicts and disputes among family members, including among abused wives and abusive husbands involved in domestic violence; heads of communes; herbal medicine healers and spiritual leaders; doctors; health care workers; teachers; leaders of the state sponsored Women's Union, Farmers Union, and Youth Union mass organizations; community elders; and officials in the criminal justice system in the community. Many of these individuals were members of families with middle income levels.

Also collected were relevant materials, reports, information, and documents from state agencies, state-supported mass organizations, local and international NGOs, and the media. Representatives of families were located with the assistance of local community members, based on their ethnicity, gender, social class position, and age. Women from each of the three ethnic groups who were abused by their husbands were located through my interviews with them, as well as through the aid of local community members who provide assistance to abused women. Community leaders were identified primarily through their participation in domestic violence prevention and intervention activities.

This qualitative study draws on a political economy of domestic violence theoretical approach in anthropology to analyze the ways that cultural, social, political, and economic forces in the upland community-and in Vietnam more broadly-influenced the experiences and perceptions of domestic violence among members of the three ethnic groups, and the community leaders' responses to this form of gender violence. According to Adelman (2004), this approach "situates domestic violence within cultural-historical context to reveal the intersection between domestic violence and (1) the organization of the polity, (2) the arrangement of the economy, and (3) the dominant familial ideology expressed normatively through state policies" (p. 46). Included in this approach was the qualitative analysis of the texts derived from the formal, semi-structured open-ended interviews conducted with research subjects from the Muong, Dao, and Kinh ethnic groups. The interviews analyzed were conducted specifically with the adult representatives of 39 families, the 15 women who have experienced domestic violence, and the 24 community officials and leaders, health care personnel, local healers, and other key informants who have participated in domestic violence prevention and intervention activities. The analysis was based on the grounded-theory approach, and entailed the identification of pertinent analytic categories, or themes, that emerged from the interviews, which are presented and discussed in the following sections. Analysis and 
interpretation of the qualitative data that was generated through this approach resulted in the argument made in this article (Bernard, 2006).

Also significant to note is that confidentiality is an important concern for all research, and is a particular concern for this study due to the sensitive nature of conducting research focusing on domestic violence or other forms of gender violence (Imam \& Akhtar, 2005). In order to maintain confidentiality and protect my research subjects, all names and some identifying information of the community and my research subjects have not been included.

\section{Results}

\section{Local approaches to domestic violence in Vietnam and global influences}

In Vietnam, through state neoliberal economic and political reforms which officially began in the mid-1980s with the implementation of doi moi policies, Vietnam became reintegrated into the global economy. Doi moi is the set of policies, often referred to as renovation, adopted by the Vietnamese government and Communist Party in 1986, which dismantled the command economy and allowed for a form of market socialism (Malarney, 2002; McCargo, 2004). In addition, the renovation policies involved a reorientation of the Communist Party and the state's role in the lives of Vietnamese people, including less state and party control over many aspects of people's everyday lives (Malarney, 2002). With political and social reforms, there has also been greater interaction of the Vietnamese government and population with the international community.

As a result of these changes, international development agency, donor organization, and local NGO processes expanded, leading the Vietnamese state and local NGOs to increase their participation in the contemporary global social movement against violence to women. In 2007, with the influence of these changes, and the support and ideas of international organizations and local NGOS, the Vietnamese state approved the first domestic violence law, called the Law on Domestic Violence Prevention and Control (Kwiatkowski, 2011a; National Assembly, Socialist Republic of Vietnam, 2007). This law had been implemented and drawn upon by community leaders and state officials in the upland community for approximately two years at the time this research was conducted.

This structural change influenced community leaders, state officials, and local residents in particular ways, not all of which resulted in substantive change in approaches to responding to and resolving cases of domestic violence. The outcome of the continuity of traditional state responses to domestic violence, particularly the mandate to reconcile husbands and wives involved in domestic violence, was shared experientially by abused women and abusive men from each of the three ethnic groups. In addition, the influence of international organizations working toward preventing gender violence against women on a global scale, and of local NGOs whose personnel has been informed by this global social movement, led to the introduction of new approaches to domestic violence in Vietnam, including in this upland community. These new approaches were often reappropriated by Vietnamese state and NGO personnel who were influenced by Western conceptions of gender violence. Examples are the creation of community safe houses in local communities to assist abused women who flee their husband's violence and community-based clubs to aid and socially support women abused by their husbands and train and coordinate volunteers working to prevent domestic violence. Each of these developments related to gender violencedomestic violence specifically - that emerged in Vietnam since the late 1990s were supported by the Vietnamese state, in part, as an element of its integration into the global economy and the broader world (Kwiatkowski, 2011a). It is within this changing cultural and social context that members of the Kinh, Muong, and Dao ethnic groups were experiencing and responding to domestic violence in their upland community.

\section{Gender and domestic violence among three ethnic groups in an upland community}

In the upland community, an elder Muong man said that, historically, Kinh people had migrated to this area several decades ago, but it was with the development of industry in the 1960s, followed by the building of a dam in the 1970s, that Kinh people began to move to this community in higher numbers. The Muong and Dao residents lived in the area, even prior to that time, along with other ethnic groups, often moving within it as they practiced shifting cultivation. Both groups became more sedentary with an increase in population and the institution of new policies of the Communist government. Since the implementation of doi moi in the 1980 s, Kinh people have continued to 
migrate into the community. Members of these three, and other, ethnic groups have shared cultural ideas and technologies, including agricultural technologies, and have intermarried as well, complicating notions of distinct ethnic boundaries among the groups. The community's economy is based on agriculture, forestry, fisheries, industry, craft production, business, tourism, and services.

While the Kinh, Muong and Dao in this upland community are identified by community members as distinct ethnic groups, members of these groups discussed both cultural and social similarities and differences that they perceived between their ethnic groups. As members of these groups have interacted, they perceived Muong culture to be most similar to Kinh culture, and Dao culture to be similar to Kinh and Muong cultures in many ways, but also different from them. The latter differences were seen to stem from Dao people's historical migration into Vietnam from China, possibly as early as the $11^{\text {th }}$ century, and to involve distinctions in the domains of language, religion, and healing (West, 2009). The drawing of these kinds of relationships are viewed by some in social evolutionary terms, with Kinh and Muong, who are constructed as similar to Kinh, perceived to be more developed than Dao (The World Bank, 2009). This kind of cultural perspective is reflected in the views of some of the community members in this study.

Patrilineal descent is prominent in the kinship practices of Dao, Muong and Kinh people of this community. In regard to labor and gender, men and women of each of the three ethnic groups commonly work outside of the home, in a variety of types of labor, such as farming, industry, transportation, business, marketing, and professional positions. Although the state in contemporary Vietnam, led by the Communist Party, promotes gender equality, patriarchal views persist in Vietnamese society. This is exemplified by the practice of gender violence and the recent promotion by both the state and popular media of a renewed emphasis on women's "traditional" domestic and family roles and responsibilities (Drummond, 2004; Kwiatkowski, 2011a; Pettus, 2003). Still, in order to assess gender as an emergent set of cultural practices to be examined in dynamic terms, it is useful to look at Dao, Muong, and Kinh women and men's own interpretations of their positions within their marriage and family (Padilla, 2011; Plesset, 2006).

\section{Perceptions of gendered power in marriage}

Mixed perceptions of gender relations within the marriages of the Dao, Muong, and Kinh individuals interviewed were found, in terms of authority and power. For instance, most of the men and women of the three ethnic groups described their marital relationships as equal. However, more Dao than Muong and Kinh women described their husbands as holding greater authority in their household. In addition, more men of all three ethnic groups described their marital relationship as equal than did women (see Table 1).

Table 1. Gender Relations within Marriage: Perceptions of Authority within the Marriages of Dao, Muong and Kinh Male and Female Representatives of Households

\begin{tabular}{lccc}
\hline Respondents & $\begin{array}{c}\text { Greater authority } \\
\text { with husband } \\
(\%)\end{array}$ & $\begin{array}{c}\text { Greater authority } \\
\text { with wife } \\
(\%)\end{array}$ & $\begin{array}{c}\text { Equal power shared } \\
\text { in marriage } \\
(\%)\end{array}$ \\
\hline Dao women & 38 & 12 & 50 \\
Dao men & 14 & 0 & 86 \\
Muong women & 0 & 17 & 83 \\
Muong men & 14 & 0 & 86 \\
Kinh women & 20 & 20 & 60 \\
Kinh men & 0 & 0 & 100 \\
\hline Totals & 14 & 8 & 78 \\
\hline
\end{tabular}

Among the women interviewed who were abused by their husbands, $60 \%$ of these women perceived their husbands to have greater authority in their marital relationship, and $40 \%$ viewed themselves to have more authority. Like the Dao women interviewed who had not been abused, Dao abused women most commonly perceived their husbands to have more authority in their marital relationship, with $80 \%$ of the Dao abused women 
expressing this view. Many of the married couples in each of the three ethnic groups interviewed shared a sense of equality in their marital relationship, but this perception of equality between spouses was not as commonly found among the abused women interviewed (see Table 2).

Table 2. Gender Relations within Marriage: Perceptions of Authority within the Marriages of Dao, Muong and Kinh Women Who Are Abused by Their Husband

\begin{tabular}{lccc}
\hline Respondents & $\begin{array}{c}\text { Greater authority } \\
\text { with husband } \\
(\%)\end{array}$ & $\begin{array}{c}\text { Greater authority } \\
\text { with wife } \\
(\%)\end{array}$ & $\begin{array}{c}\text { Equal power shared } \\
\text { in marriage } \\
(\%)\end{array}$ \\
\hline Abused Dao women & 80 & 20 & 0 \\
Abused Muong women & 40 & 60 & 0 \\
Abused Kinh women & 60 & 40 & 0 \\
\hline Totals & 60 & 40 & 0 \\
\hline
\end{tabular}

\section{Reasons offered for wife abuse}

Wife abuse was found among couples in each of the ethnic groups. Some of the reasons most commonly suggested by members of the three ethnic groups interviewed for the men's violence were men's drunkenness, jealousy, sexual relationships outside of marriage, distress over gambling losses, a lack of understanding between the wife and husband, the family's poverty, and friends of a man making negative comments about his wife.

For example, combining several of these reasons for wife abuse, one middle-aged man said, "Maybe (a man commits domestic violence) because he drinks alcohol, and if the man or the woman is jealous. If some families have a stable financial situation, domestic violence will not occur, but if the family is very poor they may experience domestic violence." A woman of the same age offered her opinion that "Many men (who commit domestic violence) gamble, and almost all of them are unfaithful to their wives, having relationships with other women." With both husband and wife working outside of the home in many households in the upland community, as noted earlier, individuals said that tensions arose between some husbands and wives if one had a job and the other did not, leading in some cases to both poverty and a lack of mutual respect for each other.

In addition, a few individuals perceived that men have a high, or hot, temper, so women should know how to make concessions to the man to prevent fighting between them (see also Rydstrom, 2003). One abused woman said, "In general, no one can accept a husband abusing his wife. But in some families I have seen that the wife is very bad, and her husband has a high temper, and when he is angry, his wife often makes him angrier. In these cases, the wife has to suffer domestic violence." She added, though, that "If a wife does something bad, it is not acceptable for her husband to hit her."

Male Dao and Muong leaders who work as members of official local reconciliation committees articulated a view held by others, such as this abused woman, that a wife or a husband could have caused the husband's violence against his wife. This view perpetuates the perception that a woman can be blamed at times for her husband's violence against her. Each of these reasons for wife abuse, suggested by members of the three ethnic groups, points to perceived social and structural causes, rather than causes stemming from cultural attributes associated with each of the three ethnic groups.

\section{Local leaders and healers' perceptions of the intersection of domestic violence and ethnicity}

As previously elaborated, there are numerous individuals involved in preventing domestic violence and assisting women who have been abused by their husband in this community. Local leaders discussed the kinds of activities they participated in that address domestic violence, including helping abused women in accessing services such as health care and legal aid, providing advice to men and women experiencing domestic violence, educating community members about this form of gender violence to prevent further violence, leading clubs to prevent domestic violence, and other activities. In the following, the perceptions of these individuals who respond to domestic violence about this form of gender violence among members of the three ethnic groups are presented.

Alterstice - Revue Internationale de la Recherche Interculturelle, vol. $3, n^{\circ} 2$ 
These perceptions depict the emphasis they placed on social and structural processes influencing husbands' abuse of their wives.

\section{No differences perceived in manifestations of wife abuse among the ethnic groups}

Most individuals interviewed who are involved in domestic violence activities did not perceive differences in manifestations of wife abuse among members of each the three ethnic groups. A number of individuals providing health care within the community were interviewed. While local Dao and Muong spiritual leaders and healers and Kinh healers provide services to people within their community, the healers interviewed said that only a few, or in some cases no, abused women have sought them out to heal their injuries derived from their husband's violence.

For instance, taking a look at the views of healers from each ethnic group, one Dao healer said that one or two couples in a year may ask him for assistance with domestic violence. A Muong healer said she has given advice to couples experiencing domestic violence, but that she was called upon as an elder in her community rather than as a healer. She said that issues surrounding domestic violence are discussed in the Vietnam Association of the Elderly, or the Elders Union. The Elders Union often addresses relationships among family members and the state-promoted concept of family happiness.

Some healers were called upon by abused women for assistance to a greater extent than others. Another Dao healer said that she had both treated and given advice to some abused women from each of the three ethnic groups who had sought treatment from her for bruises. She also let some of the abused women sleep at her home overnight. But she said that she provides advice because she pities the women, not because she is a healer. Another Muong healer, who combines Muong and Kinh healing and has assisted abused women from each of these two ethnic groups, has not treated Dao abused women. She thinks the reason for this is simply that Dao people do not live near her home.

As discussed, most local spiritual leaders and healers of each ethnic group said that abused women in this community call upon them as healers for treatment and assistance only minimally, yet some assist these women on what they interpreted to be a more social level. Based on both their personal and professional experiences, the spiritual leaders and healers said they do not perceive differences in the women's experiences of domestic violence relative to their ethnicity.

Biomedical professionals also interact with abused women in this community, and do so more often than local healers, providing health care and advice to them. In general, abused women tend to access treatment from biomedical professionals when they cannot treat themselves, local healers cannot cure their injuries, or when others accompany them to a hospital or clinic, such as police officers or family members. Of four female biomedical professionals interviewed, three related that in regard to domestic violence there are no differences among the members of the ethnic groups, and that all are the same in terms of the reasons for and manifestations of the abuse. For example, one biomedical professional said that the occurrence of domestic violence among members of these ethnic groups depends on their knowledge, not on their ethnicity. A Women's Union leader who assists couples experiencing domestic violence said that a recent survey of about one hundred women conducted by a Women's Union office in the community showed the rates of cases of domestic violence among the Kinh, Dao, and Muong ethnic groups to be largely the same, with the rate among members of the Kinh ethnic group to be a bit higher. ${ }^{1}$ She stressed, however, that she interpreted the survey as pointing to little difference in the rates of domestic violence among the three ethnic groups.

These expressions reflect the views of most healers, health care professionals, officials, leaders and professionals interviewed in this community, who did not perceive differences in experiences of domestic violence relative to ethnicity.

\footnotetext{
${ }^{1}$ Unfortunately, a copy of the survey could not be located in order to acquire the survey results.
} 


\section{Differences perceived in manifestations of wife abuse among the ethnic groups with diverse structural influences}

Assertions of higher rates of domestic violence among particular ethnic groups with modern structural influences

There were some individuals who had assisted abused women, however, who did perceive differences in the manifestations of wife abuse among members of the three ethnic groups. For instance, one of the four biomedical professionals observed members of the Kinh ethnic group to have more serious cases of domestic violence, compared to Muong and Dao. This Kinh biomedical professional reasoned that this stemmed from frequent arguments among Kinh couples. She further perceived Muong couples to experience domestic violence less frequently and severely than Kinh couples, but more than Dao couples. She noticed Dao husbands and wives often coping with difficult situations, including poverty, without becoming angry and arguing with each other. She also said that, until recent years, Dao people had not had many relationships with individuals outside of their communities, nor much access to the media or to convenient forms of transportation. She thought this reduced access to outside influences led Dao men to be less likely to abuse their wives, to have sexual relationships outside of their marriage, and to be subjected to other men's negative comments about their wives.

Another professional interviewed was a Muong official in the criminal justice system who has responded to cases of domestic violence and worked with couples involved. He suggested that Kinh husbands and wives have a higher rate of domestic violence. In his view this is due to their living on or near a main road and running businesses in a more anonymous setting, where opportunities for sexual relationships outside of their marriage may be more prevalent. He said these relationships lead to arguments or conflicts between spouses and within their family. He said that for members of each of the three ethnic groups, another reason for conflicts in marriage is differences in access to stable employment between men and women, with either a wife or a husband having better opportunity for employment.

Perceptions of less domestic violence within "less developed areas"

A few community officials and professionals perceived some ethnic groups to be living in areas that are "less developed," referencing modern ideas of development in Vietnam, and asserted that this results in a lower level of domestic violence among members of these ethnic groups. For example, the Muong official in the criminal justice system offered his view that Dao and Muong families commonly live in less developed areas and in closer proximity to each other, and that they tend to resolve conflicts through community norms, often giving advice and encouragement to each other. A Muong school teacher held a similar view, as did the Kinh biomedical professional. The teacher knew of more cases of domestic violence among Kinh couples than among couples identified with the other two ethnic groups, and she had not learned of any cases of domestic violence among Dao parents of the children in her school or Dao couples in her community. She perceived the Dao people to be very kind to each other, and asserted that they often have a "simple" outlook on their life. She observed that Dao children finish their education, marry, and live their adult lives together interacting primarily with other Dao community members.

Modernity viewed as lessening domestic violence

On the other hand, a male Dao community leader surmised that wife abuse had decreased in his community because young people currently have more knowledge about domestic violence and its detrimental effects, and live a modern lifestyle.

As noted, these examples illustrate perceived differences in experiences and expressions of domestic violence relative to ethnicity. What is striking about these discussions is that most link economic and political changes to shifts in practices and conceptions related to domestic violence, gender relations, marital relationships, and modernity. 


\section{Approaches to addressing domestic violence in an ethnically diverse community}

A number of these professionals and community leaders provided assistance to abused women of the three ethnic groups and addressed the abuse with their husbands. While these individuals responded to domestic violence among members of different cultural groups, the only need or difficulty they reported experiencing during this process was that of locating an individual who spoke the language(s) of the couple who was experiencing domestic violence, particularly among Dao and Muong couples. This need arises at times, particularly for Kinh professionals and community leaders, since not all Dao and Muong people speak the Vietnamese language spoken by members of the majority Kinh ethnic group. In spite of this perceived difficulty, these professionals and community leaders did not recognize a need to address domestic violence cases in a culturally specific manner or to ask an individual from the same ethnic group to assist the couple.

As a whole, of the 24 community leaders interviewed, only five discussed differences they perceived in experiences of domestic violence when comparing members of the three ethnic groups. Among these five were community leaders, some of whom were associated with the state and others who were not. As previously argued, when they described their perceptions, the differences they elaborated mainly stemmed from the social structural conditions and political economic contexts within which the members of each ethnic group enacted their everyday lives, rather than from essentialized ideas of cultural attributes associated with particular, fixed ethnic groups. In addition, their perceptions of differences were largely based on their own everyday experiences and observations with individuals experiencing domestic violence, rather than on more systematically collected evidence, which is not available. In general, cultural differences between the three ethnic groups were not perceived by these community leaders to have a great effect on experiences of domestic violence among members of these ethnic groups living in their community.

\section{Discussion: The Vietnamese state, ethnic groups, and domestic violence}

\section{State orientations to ethnic diversity}

Historically, upland populations in Vietnam were perceived in changing ways by diverse groups, who often used labels to identify upland groups that had cultural assumptions and political motivations driving them. In discussing the Central Highlands of Vietnam, Oscar Salemink (2003) writes that prior to the French colonial period, the indigenous population was referred to by lowland Vietnamese and other groups with terms meaning "savage," a concept adopted by early French colonizers. Terms such as Montagnards (mountain dwellers) and Highlanders became more acceptable during the later French colonial period, and were also used by Americans after 1955. Communist scholars and politicians in Vietnam referred to these groups as "ethnic minorities," following some of the criteria of Stalinist national theory that makes no distinction between "nation" and "ethnic group" (Salemink, 2003, p. 29).

The contemporary communist government of Vietnam refers to fifty-three ethnic minority groups and the Kinh ethnic majority group. While these ethnic labels are official ethnic classifications, ethnic group boundaries and cultural differences are not actually so clearly defined and tend to be more fluid. Some ethnic group classifications were imposed on people by academics and the Vietnamese state's classification systems. With an essentialized view of culture, the Vietnamese state has perceived Vietnam's ethnic minority groups to have a cultural level that is lower than that of the Kinh ethnic majority group (Asian Development Bank, 2002; Salemink, 2003; The World Bank, 2009). Some elements of ethnic minority groups' cultural practices are viewed by the state as backward or superstitious in contrast to modern science, framed, in part, by a social evolutionist discourse, and as in need of being changed. Yet other elements of ethnic minority groups' cultural practices have been viewed as needing to be selectively preserved by the state, as a process involving both disciplining of the ethnic minority populations and folklorization of culture (Asian Development Bank, 2002; Salemink, 2003, p. 277-278). Through these and other processes, such as state sedentarization programs in upland areas, ethnic minority groups have been subject to civilizing practices of the state, so that they may become "civilized" citizens of Vietnam and included in the state system (Salemink 2003, p. 270, 295). The promotion of development among ethnic minority communities has been a recent and continuing development goal of the Vietnamese state, as well as of international development and 
donor organizations (Asian Development Bank, 2002; Office of the United Nations Resident Coordinator, 2002; The World Bank, 2009).

\section{Structural forces, the state, and perceptions of domestic violence}

The intersection of the Vietnamese state's approaches to ethnic minority groups, a lack of distinct ethnic group boundaries, and the long-term social interaction of members of the three ethnic groups within the upland community discussed in this article may have influenced local leaders and healers to perceive the contemporary problem of domestic violence among ethnic groups in their community as primarily due to broader social structural forces and political and economic changes, rather than as informed by essentialized cultural characteristics associated with each group.

For instance, in addition to the perceptions presented earlier, the official in the criminal justice system who was previously introduced said that, based on his interpretation of the new domestic violence law, when a man who has abused his wife is fined, he is not fined because he committed violence against his wife, but rather because he fractured the security of the community. This interpretation of the law gives priority to the security of the community over the safety and security of abused women. Regarding approaches to cases of wife abuse by state agencies, this official said he has observed that the first time a man abuses his wife he has simply been warned to stop this behavior by police officers. If the man commits another act of violence against his wife, in recent years he usually would be fined 200,000 Vietnamese dong, which is currently approximately 10 U.S. dollars. With state officials using this approach over the last three years, he said there had been no cases of domestic violence involving charges made by women against their husband at a police station in his area, and no arrests of abusive men. He said that there had been only one case of domestic violence that he was aware of involving police officers in his area during this time, wherein a woman had been beaten by her husband and treated at a local hospital for injuries he inflicted on her. He said that, in his view, it was the woman's own fault that her husband committed violence against her, and that she conveyed this to police officers. Members of the commune-level People's Committee, the Women's Union, and other state sponsored unions had visited this woman to encourage and advise her, and they resultantly convinced her to reconcile with her with husband. She ultimately did not press charges against her husband with the police, and the official said she now lives with her husband.

He further revealed that there had been about five or six other cases of domestic violence during the last year in his community to which police officers or members of a local security board responded at the couples' homes. He said that in all of these cases, the couples had reconciled with the help of local reconciliation committee members.

He also suggested that one important effect of the new domestic violence law had been to make police officers' work much easier, because they no longer have to explain or justify their intervention in domestic violence conflicts. He said, "Now when we reconcile the couple, we base the reconciliation process on the law. The people living in the commune are more aware of domestic violence and the law because they must follow this law, and the commune leaders have also learned a great deal about the domestic violence law." Through one of the articles of the domestic violence law, which mandates community leaders (including police officers, reconciliation committee members, Women's Union leaders, government officials, and others) to make efforts to reconcile couples experiencing domestic violence, women continue to be pressured to reconcile with their abusive husband without adequate counseling of the husband, and with no assurance the violence will end (National Assembly, Socialist Republic of Vietnam, 2007).

There are more extensive procedures for fining and educating men who have committed domestic violence with a weapon, seriously harmed their wives physically, or who have been approached by police officers more than once for committing violence against their wives. However, the normative practices of simply warning abusive husbands during the first police intervention, later fining abusive husbands following a second police intervention, attempting to convince the couple to reconcile in all cases of domestic violence, and, more recently, using the domestic violence law to justify these police responses to domestic violence, have combined to create a structural force that has a significantly negative effect on the experiences of domestic violence among abused women of each of the three ethnic groups, as they are often subjected to continued violence from their husband.

Alterstice - Revue Internationale de la Recherche Interculturelle, vol. 3, $n^{\circ} 2$ 
The Vietnamese state's current legal structure, including the new domestic violence law, inadvertently allows police officers to not take violence committed by men against their wives very seriously-particularly the first time they intervene in a case of a man abusing his wife. This makes it easier for a man to continue abusing his wife with no or very minor punishment, and supports the social pressure exerted on an abused wife to remain in her marriage and household. While this official in the criminal justice system blamed a woman for her husband's violence against her in one case that he discussed, he also pointed to legally legitimate processes which pressure women to remain with their abusive husbands and make them increasingly vulnerable to continued violence from their husbands.

\section{Difficulties preventing domestic violence}

To exemplify this problem further, one Farmers Union leader, who incorporates discussions about domestic violence and its prevention in Farmers Union meetings attended by both men and women, said that one of the Union members' problems in trying to prevent domestic violence is that "no one punishes the men who commit domestic violence." Members of local reconciliation committees in the research community also stressed the importance of reconciling the couple as the main priority of their work, in order to avoid divorce and the anticipated social problems for children of divorced parents. The majority of the other community leaders also discussed the importance of reconciling couples who experience domestic violence, since they said they were following one of the mandates of the current domestic violence law, which reinforced the existing state approach to addressing cases of domestic violence.

Among the fifteen abused women interviewed, only three said that they had been approached by members of the reconciliation committee. A common result of pressuring abused women to reconcile with their abusive husband is continued violence, as noted above. For example, in one case, a Muong woman who had been severely beaten by her husband on a regular basis for almost three decades, was visited by the reconciliation committee. Her husband had hit and kicked her, and used knives and other objects to attack her. She had expressed to her husband her desire to divorce him. However, she said, "He says that is fine, but before you can divorce me, maybe you will become blinded or disabled." This threat of violence and injury has prevented her from seeking a divorce. She has called on the head of her village and police officers to help her. She said, "They came and told my husband that 'a wife and husband should help each other in a good family. And, you are the husband. You should not beat her because she is a woman who is much weaker than you.' Sometimes other relatives and neighbors also come to explain this to him. I have spoken with all of these people to get help from them." Despite these discussions focused on ending her husband's violence and building a good or happy family, this woman's husband was still abusing her at the time that she was interviewed for this study.

\section{Alternative approaches to addressing domestic violence}

Rather than emphasizing punishment, however, one village organized a Domestic Violence Prevention Club in 2007 in response to the passage of the new domestic violence law. The club meets to discuss the domestic violence law among the members of the club, composed of men and women from the Muong, Kinh, and Dao ethnic groups. According to the club leader, they also counsel and reconcile couples within the club and in the village who are experiencing domestic violence, work to prevent domestic violence, and engage in social activities on special occasions and holidays. This club is one mechanism for implementing the domestic violence law at the local level, and educating community members about domestic violence and the law. Also, a French international organization is beginning to support and develop other programs focusing on domestic violence in this community, and provide additional support for this club. The members of the club include married and unmarried community members.

The leader of this Domestic Violence Prevention Club said, "The (government) People's Committee made a decision to establish this club to be a model in this village...Now we have more than 40 members and we have meetings every three months. If there are some cases of domestic violence among our members, we will present the cases and discuss them in the meetings. The officers of the club include three members, the leader, assistant leader, and secretary. If any of the male members are abusing their wives, I will call on the man to ask for the reason and to warn him once. The second time the man commits domestic violence, we will present the case to all members of the club and discuss it. If this man commits domestic violence a third time, we will punish him according to the laws 
of the village and the rules of the club." This could involve fines or, less frequently, imprisonment. During club meetings, the officers and members discuss the domestic violence law and other relevant government laws, and, toward the end of the meetings, they discuss agricultural production. One way in which this club differs from more traditional state reconciliation processes is that it can provide ongoing community support for the abusive husband and abused wife, which does not usually occur through the reconciliation committee. This could potentially aid in ending a husband's violence.

However, some difficulties in running these clubs over time discussed by this club's leader and a leader of a Women's Union Club for Family Happiness include convincing abusive husbands to join the clubs and attend the meetings, reducing husbands' fears that their wives will reveal their family's problems at the club meetings, (potentially including a husband's abuse), developing trust among abused women so they will feel comfortable sharing their experiences of abuse with other club members, acquiring adequate funding to support club activities, and locating a place to hold regular meetings of the club. Other issues of concern that were not discussed by the club leaders are the continued emphasis among club leaders on reconciliation of couples experiencing domestic violence, and the long periods of time between the meetings of some clubs (such as three months). Other communes have developed programs and discussions focusing on domestic violence within other existing clubs and organizations as well, such as state supported Farmers Clubs and the Clubs for Family Happiness mentioned above. Regarding ethnicity, the club membership is usually not homogeneous with respect to ethnic identification. Instead, it is often based on residence within a political unit, such as a commune. In addition, club leaders did not mention that they explored manifestations of domestic violence associated with particular ethnic groups during their meetings.

Through these clubs, members try to influence the views on domestic violence held by men and women of a variety of ethnic groups and to prevent new instances of men abusing their wives. However, despite these important new approaches to preventing domestic violence, many of which were influenced by international organizations, with the state reconciliation process still in place through the new domestic violence law and within these clubs, abused women remain vulnerable to their husband's violence.

\section{Conclusion}

In this article, perceptions of and responses to domestic violence among members of three ethnic groups living in an upland community, two of which are considered ethnic minority groups, were explored. The three ethnic groups were found not to be highly differentiated from one another by community leaders when they assessed the problem of domestic violence, and, when the ethnic groups were found to be differentiated, changing social structural forces were perceived to be the primary sources of that differentiation. In light of this finding, this study argues that while cultural forces shape practices and experiences of domestic violence, social structural forces are also perceived to play a significant, and, in some cases, more important role in influencing the expressions and experiences of domestic violence. This is illustrated by the difficulty women still face in locating protection from their husband's violence even with the implementation of the new domestic violence law. This problem more significantly impacts women's vulnerability to the violence and results in negative health and social effects than differences experienced due to identification with a specific ethnic group.

Still, in this community social structural forces intersect with shared cultural conceptions to influence domestic violence, such as dominant discourses of gender, marriage, family, and violence which support husbands' abuse of their wives. These include Confucian influenced notions of husbands' superiority over wives, women being blamed for their husband's violence against them, women internalizing or publicly supporting this idea, and men and women accepting the notion that husbands have a high or hot temper that is not easily controlled and is expressed through violence. This study argues that the intersection of state power, structural processes, and shared cultural conceptions of gender, marriage, family and violence has played an integral role in shaping abused women and abusive men's experiences of domestic violence among members of the three ethnic groups living in the research community.

Alterstice - Revue Internationale de la Recherche Interculturelle, vol. 3, $n^{\circ} 2$ 
The new domestic violence law does not unambiguously aid in reinforcing traditional approaches to domestic violence, however. For instance, calls for further education of the general public and professionals on the issue, and particularly of children and youth in the public schools, are found in the domestic violence law and may eventually lead to a reduction in this violence. Media coverage of the issue of domestic violence is also encouraged in the law, and there has been a significant increase in stories and programs focusing on domestic violence in print media, radio, and television in recent years. The new law also calls for improved medical services for victims of domestic violence, which can aid these individuals on multiple levels, including physically, emotionally, and socially, particularly where medical care combines psychological and social support services with physical care. The law also advocates the provision of community safe houses for domestic violence victims. Local and international NGOs and international donor organizations have been working in Vietnam, at least since the late 1990s, to implement new programs to try to prevent domestic violence and protect and assist women abused by their husband. Perhaps most significant in regard to problems addressed in this article is that government officials, and potentially some members of local NGOs and other professionals, will have the opportunity to address what they perceive to be problems with the new domestic violence law during a formal five year review. This review has the potential to change articles of the law or procedures to implement the law which could offer greater protection for abused women.

\section{Acknowledgements}

I would like to extend my deep appreciation to Dr. Nguyen Thi Hoai Duc, director of the Institute for Reproductive and Family Health (RaFH) of Hanoi, who provided me affiliation with RaFH and excellent assistance during my research. I am most grateful to the members of the Vietnamese community who participated in my research, generously shared their experiences and insights with me, and made this publication possible. I appreciate also the perceptive comments of Donna Goldstein on an earlier version of this article, which I presented at the American Anthropological Association Annual Meeting in 2011. I would also like to thank the editor of this special issue, Ghayda Hassan, for her valuable guidance and efforts toward developing this special issue, and two anonymous reviewers for their helpful and thoughtful suggestions.

\section{References}

Adelman, M. (2004). The battering state: Towards a political economy of domestic violence. Journal of Poverty 8(3), 45-64.

Alcalde, C. M. (2010). The woman in the violence. Gender, poverty, and resistance in Peru. Nashville: Vanderbilt University Press.

Asian Development Bank. (2002). Indigenous peoples/ethnic minorities and poverty reduction Viet Nam. Manila, Philippines: Asian Development Bank.

Bernard, R. H. (2006). Research methods in anthropology: Qualitative and quantitative approaches (4th ed.). Lanham, MD: AltaMira Press.

Burbank, K. V. (1994). Fighting women: Anger and aggression in aboriginal Australia. Berkeley: University of California Press.

Drummond, L. (2004). The modern “Vietnamese woman”: Socialization and women's magazines. In Drummond, L. \& Rydstrøm, H. (Eds.), Gender practices in contemporary Vietnam (pp. 158-178). Singapore: Singapore University Press.

Gammeltoft, T. (1999). Women's bodies, women's worries: Health and family planning in a Vietnamese rural community. Richmond, Surrey, GB: Curzon Press.

Hautzinger, S. J. (2007). Violence in the city of women: Police and batterers in Bahia, Brazil. Berkeley: University of California Press.

Hoang, B. T. (Ed.). (2005). Domestic violence in Vietnam and the role of the mass media. Ha Noi: The Gioi Publishers. 
Imam, U. \& Akhtar, P. (2005). Researching Asian children's experiences of domestic violence: The significance of cultural competence and shared ethnicities of participants in the research process. In Skinner, T., Hester, M. \& Malos, E. (Eds.), Researching gender violence: Feminist methodology in action (pp. 66-86). Devon, UK: William Publishing.

Kwiatkowski, L. (2011a). Prolonging suffering: Domestic violence, political economy, and the state in northern Vietnam. Gendered Perspectives on International Development (GPID) Working Paper No. 299. East Lansing: Michigan State University.

Kwiatkowski, L. (2011b). The cultural politics of a global/local health program for battered women in Vietnam. In Wies, J. R. \& Haldane, H. J. (Eds.), Anthropology at the front lines of gender-based violence (pp. 139-164). Nashville: Vanderbilt University Press.

Kwiatkowski, L. (2011c). Engaging the challenges of alleviating wife abuse in northern Vietnam. In Brunson, J. (Ed.), Special issue on anthropological encounters with intimate partner violence: Reflections on our roles in advocating for a safer world. Practicing Anthropology 33(3), 32-37.

Kwiatkowski, L. (2011d). Domestic violence and the "happy family" in northern Vietnam. Anthropology Now 3(3), 20-28.

Kwiatkowski, L. (2012). Negotiating battered women's marginality in health care: Changing approaches to domestic violence in northern Vietnam. In Browne-Miller, A. (Ed.), Violence and abuse in society: Understanding a global crisis (Vol. 4, pp. 403-427). London: ABC-CLIO/Praeger.

Lazarus-Black, M. (2007). Everyday harm: Domestic violence, court rites, and cultures of reconciliation. Urbana: University of Illinois Press.

Le, T. P. M. (1998). Violence and its consequences for reproductive health: The Vietnam case. South and East Asia Regional Working Papers Nos. 12, 15, 34-42. Hanoi: The Population Council.

Le, T. P. M. (2002). Gender and gender-based violence: How health providers can help female victims. Hanoi: Encourage Project, Consultation of Investment in Reproductive Health.

Le, T. Q. (1992). Some views on family violence. Social Sciences 4, 81-87.

Le, T. Q. (1996). Domestic violence in Vietnam and efforts to curb it. In Barry, K. (Ed.), Vietnam's women in transition (pp. 263-274). New York: St. Martin's Press.

Le, T. Q. (2000). Domestic violence in Vietnam: Context, forms, causes, and recommendations for action. Chiangmai, Thailand: Asia Pacific Forum on Women, Law and Development.

Le, T. Q. (2004). Gender-based violence in family. Study cases in Thai Binh, Phu Tho and Hanoi. Hanoi: Research Centre for Gender and Development, University of Social Sciences and Humanities.

Luke, N., Schuler, S. R., Bui, T. T. M., Pham, V. T., \& Tran, H. M. (2007). Exploring couple attributes and attitudes and marital violence in Vietnam. Violence Against Women 13(1), 5-27.

Malarney, S. K. (2002). Culture, ritual and revolution in Vietnam. Honolulu: University of Hawai'i Press.

McCargo, D. (2004). Introduction. In McCargo, D. (Ed.), Rethinking Vietnam (pp. 1-12). New York: RoutledgeCurzon.

Merry, S. E. (2006). Human rights and gender violence: Translating international law into local justice. Chicago: The University of Chicago Press.

Merry, S. E. (2009). Gender violence: A cultural perspective. Malden, MA; Oxford: Wiley Blackwell Publishing.

National Assembly, Socialist Republic of Vietnam. (2007). Law on domestic violence prevention and control. Law No.: 02/2007/QH12. Hanoi: National Assembly, Socialist Republic of Vietnam.

Nguyen, D. V., Ostergren, P., \& Krantz, G. (2008). Intimate partner violence against women in rural VietnamDifferent socio-demographic factors are associated with different forms of violence: Need for new intervention guidelines? BioMed Central Public Health 8, 55-65. 
Nguyen, T. H. D., Vu, P. N. T., \& The Centre for Reproductive and Family Health Project Officers. (2001). Domestic violence against women and attitudes, practices of health workers (Case studies in Hanoi and Ninh Binh provinces). Hanoi: The Centre for Reproductive and Family Health (RaFH) and the New Zealand Embassy.

Office of the United Nations Resident Coordinator. (2002). Gender Briefing Kit, The United Nations in Viet Nam. Hanoi: Office of the United Nations Resident Coordinator.

Padilla, M. B. (2011). From sex workers to tourism workers: A structural approach to male sexual labor in Dominican tourism areas. In Browner, C. H. \& Sargent, C. F. (Eds.), Reproduction, globalization, and the state: New theoretical and ethnographic perspectives (pp. 159-174). Durham: Duke University Press.

Parson, N. (2013). Traumatic states: Gendered violence, suffering, and care in Chile. Nashville: Vanderbilt University Press.

Pettus, A. (2003). Between sacrifice and desire: National identity and the governing of femininity in Vietnam. New York: Routledge.

Phan, T. T. H. (2008). Sexual coercion within marriage in Quang Tri, Vietnam. Culture, Health \& Sexuality 10, S177S187.

Plesset, S. (2006). Sheltering women: Negotiating gender and violence in Northern Italy. Stanford: Stanford University Press.

Romedenne, M. \& Vu, M. L. (2006). Domestic violence: The Vietnamese shift. Ha Noi: The United Nations Population Fund and the Swiss Agency for Development Co-operation.

Rydstrøm, H. (2003). Encountering "hot" anger: Domestic violence in contemporary Vietnam. Violence Against Women 9(6), 676-697.

Salemink, O. (2003). The ethnography of Vietnam's central highlanders. A historical contextualization, 1850-1900. Honolulu: University of Hawai'i Press.

The World Bank. (2009). Country social analysis: Ethnicity and development in Vietnam. Washington, D.C.: The World Bank.

Vu, M. L., Vu, T. H., Nguyen, H. M., \& Clement, J. (1999). Gender-based violence: The case of Vietnam. Hanoi: The World Bank in Vietnam.

West, B. A. (2009). Encyclopedia of the peoples of Asia and Oceania. New York: Infobase Publishing. 